\title{
Modeling Volatility in the Stock Markets using GARCH Models: European Emerging Economies and Turkey
}

\author{
Erginbay Ugurlu ${ }^{1}$, Eleftherios Thalassinos ${ }^{2}$, Yusuf Muratoglu ${ }^{3}$
}

\begin{abstract}
:
This paper examines the use of GARCH-type models for modeling volatility of stock markets returns for four European emerging countries and Turkey. We use daily data from Bulgaria (SOFIX), Czech Republic (PX), Poland (WIG), Hungary (BUX) and Turkey (XU100) which are considered as emerging markets in finance. We find that GARCH, GJR-GARCH and EGARCH effects are apparent for returns of PX and BUX, WIG and XU whereas for SOFIX there is no significant GARCH effect. For both markets, we conclude that volatility shocks are quite persistent and the impact of old news on volatility is significant. Future research should examine the performance of multivariate time series models while using daily returns of international emerging markets.
\end{abstract}

\footnotetext{
${ }^{1}$ Instructor Ph.D., Hitit University, FEAS, Department of Economics

${ }^{2}$ Professor, Department of Maritime Studies, University of Piraeus, Chair Jean Monnet, e-mail:thalassic@unipi.gr

${ }^{3}$ Research Assistant, Gazi University, FEAS, Department of Economics
} 


\section{Introduction}

The European emerging countries are mostly interested in macroeconomic and finance area. The countries present different research area because of the specific features determined by the transition process to the market-oriented economy which can be valued more than 50 billion EUR that has great opportunity for the companies of the developed countries (Triandafil and Brezeanu, 2008). After a 52-year break, the first session of the stock exchanges of Warsaw, Budapest, Prague was held on April $16^{\text {th }}, 1991$, June $21^{\text {st }} 1990$ and April $6^{\text {th }}, 1993$ respectively. As being the first establishing market, Poland is emerged to be a symbol of developed capitalist economies among the leading Central and Eastern European countries (CEECs) (Nivet, 1997). Among all Central European markets; Czech Republic, Hungary, Poland and Slovakia have an advanced capital markets, greater political stability and rapid economic growth (Haroutounian and Price, 2010; Svejnar 2002).

Financial markets, mainly stock exchanges, play an important role in the process of economic growth and development. Modeling volatility is important issue in financial markets and it has drew the interest of academics and practitioners over the last three decades. There are many studies and various models about volatility in financial data. Financial data have shown that the conditional distribution of highfrequency returns includes several features including excess of kurtosis, negative skewness, and temporal persistence in conditional movements. To accommodate them, econometricians have developed tools at modeling and forecasting volatility.

Our paper examines the volatility of five emerging stock markets in Europe that is Bulgaria, Czech Republic, Poland, Hungary and Turkey ${ }^{4}$ using GARCH, GJRGARCH and EGARCH Models with daily data referring to the period between 08.01.2001 20.07.2012.

As it is noted in Hajek (2007); studies (Filer and Hanousek ,1996; Dockery and Vergari, 1997; Worthington and Higgs, 2003; Žikeš, 2002) of the Central European market begun to emerge in the second half of the 1990s. Main researches about European emerging markets volatility are Emerson et al. (1997), Shields (1997), and Scheicher (1999). While Emerson et al. (1996) provides a model for Bulgarian stock market and Scheicher (1999) studies Polish stock returns, Shields (1997) deals with modeling returns for the Warsaw and Budapest stock exchanges returns. On the other hand, Harvey (1995), Bekaert and Harvey (1995), Bekaert and Harvey (1997) and Choudhry (1996) analyse emerging markets in the Mediterranean, Asia, South America or Africa. Scheicher (2000) analyses the movements of the short rates of

\footnotetext{
${ }^{4}$ In our and many papers Bulgaria, Czech Republic, Poland, Hungary are named as a East European Emerging countries, Bulgaria, Czech Republic, Poland, Hungary and Turkey are named as the European Emerging countries. However, some papers such as Samitas et al. (2007) and Syriopoulos and Roumpis (2009) also called Turkey and/or Bulgaria as a Balkan stock markets.
} 
emerging markets in Central and Eastern Europe and finds that the short rates in Prague, Warsaw and Budapest do not interact with the benchmark instantaneous rate in Germany. Moreover, Scheicher (2000) discusses integration of stock markets in Hungary, Poland and the Czech which are named as principal emerging stock markets in Europe in the paper. The author estimates a VEC model and modeling its volatility with a Multivariate GARCH (M-GARCH) model. The findings show that countries which are investigated have limited interaction and their volatility reveals a regional character.

Vošvrda and Žikeš (2004) use GARCH-t model to determine the volatility of returns of the Czech, Hungarian and Polish stock markets by using weekly data gathered from the period of 1996-2002. They use index series instead of their returns and after ARCH test except for the Hungarian BUX index, both tests clearly indicate the presence of a conditional heteroskedasticity in the estimated residuals. Although the null hypothesis that the shocks to returns have symmetric impact on volatility cannot be rejected for WIG and PX-50, the null hypothesis of risk-neutrality is rejected for BUX, PX-50.

Hajek (2007) tests the Efficient Market Hypothesis on the PX-50 and PX-D index and closing values and stock closing prices on the Prague Stock Exchange are analysed for 1995-2005 period for monthly, weekly and daily data ${ }^{6}$. It is concluded that the time-variable variance is typical for time series of the Czech index and stock price changes. Therefore, Central European market testing such as Czech market heteroskedasticity-consistent methodology must be applied to avoid significant biases.

Syriopoulos (2007) investigates the relationships between Czech Republic, Hungary, Poland, Slovakia as the examples of Central and Eastern Europe (CEE) stock markets and Germany, US as developed stock markets over the period 1997-2003. While, in the long run, the results show a relationship between the CEE and the developed stock markets, in the short run, the US stock market exerts a stronger impact than the German market on the CEE stock markets.

Another paper which examines the volatility in Central European markets is the study of Haroutounian and Price (2010). They analyse the Czech Republic, Hungary, Poland and Slovakia by using both univariate and multivariate GARCH models that are GARCH, NGARCH, EGARCH, GJR-GARCH, AGARCH, NAGARCH and VGARCH. The findings do not reveal any asymmetric effects in the markets. Although they mainly conclude that strong GARCH effects are apparent for all four markets, it is found that three out of seven specifications of conditional volatility are not for the market of the Czech Republic.

\footnotetext{
${ }^{5}$ PX-50 and PX-D indices are merged into the PX index in 2006.

${ }^{6}$ Time series of monthly returns would be insufficiently long and therefore it has been excluded from the analysis.
} 
Rockinger and Urga (2012) employ a model by Kalman Filter and study the model residual by GARCH for Czech, Polish, Hungarian, and Russian stock markets as examples of transition economies and American, German and British stock markets as examples of established economies. Although they focus on a sample of Central and Eastern European Financial Markets (CEEFM) ${ }^{7}$, they prefer to use only these four countries. It is stated that other CEEFM countries are available for a quite limited period of time and they have very high barriers for international capital flows. The model results are very similar for the Czech Republic, Hungary, and Poland. The results show that for these countries, whereas Germany until spring 1995 and U.S. has no effect, the United Kingdom always played an important role in these markets.

The rest of this paper is organized as follows: The next section gives some details about the data and summarizing the statistical properties of returns. The third section gives brief information about ARCH/GARCH models and the estimation results are presented in the fourth section. The fifth and the final section summarizes and concludes the paper

\section{Data}

This paper is formed by daily observations in stock exchanges of selected European emerging markets which are Bulgaria, Czech Republic, Hungary, Poland and Turkey covering the period 08.01.2001 -20.07.2012 by the data collected from Reuters. These stock exchanges are Bulgarian Stock Exchange (SOFIX) ${ }^{8}$, Prague Stock Exchange Index (PX), Budapest Stock Index (BUX), Warsaw Stock Exchange $(\mathrm{WIG})^{9}$ and Istanbul Stock Exchange National 100 Index (XU100) respectively. We use returns to denote proportionate price change over a stock exchange indices interval. In parallel with Yu (2002), return (r) is defined as natural logarithm of prize relatives as follows:

$$
r=\log \left(\frac{x_{t}}{x_{t-1}}\right)
$$

where $\mathrm{X}_{\mathrm{t}}$ is capital index. Thus, return variables are defined as RSOFIX, RPX, RBUX, RWIG, and RXU. The daily returns for both indices (presented in Figure 1 and Figure 2, Figure 3, Figure 4 and Figure 5) are shown in the graphs of those stock exchange indices and their returns.

\footnotetext{
${ }^{7}$ Czech Republic , Poland, Hungary, Russia, Bulgaria, Slovenia, Romania, Croatia and Estonia.

${ }^{8}$ Sofia Stock Indexes

${ }^{9}$ Warszawski Indeks Gieldowy
} 

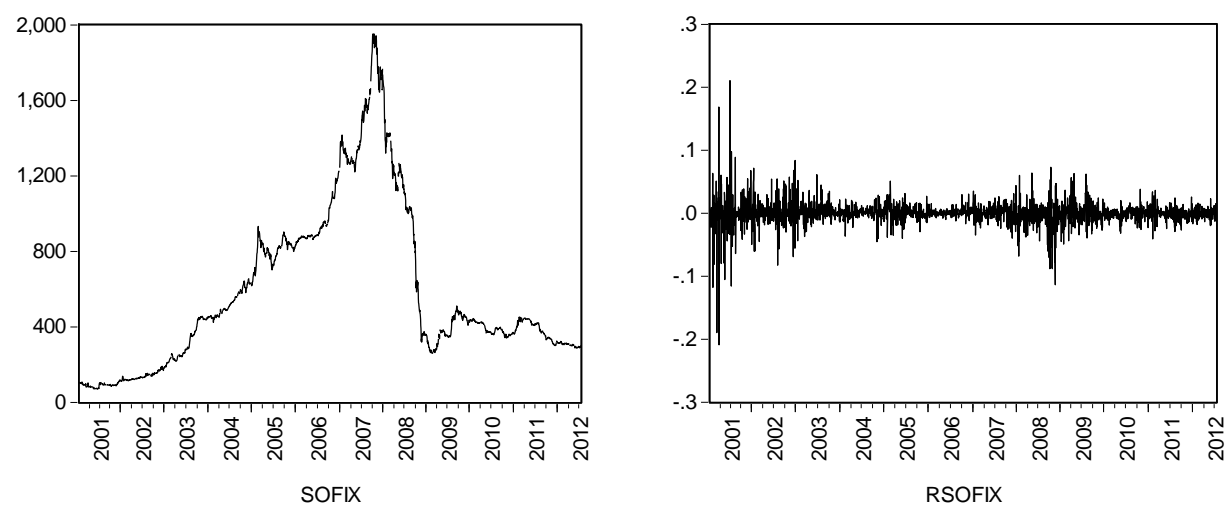

Figure 1: Bulgaria, SOFIX daily prices and returns
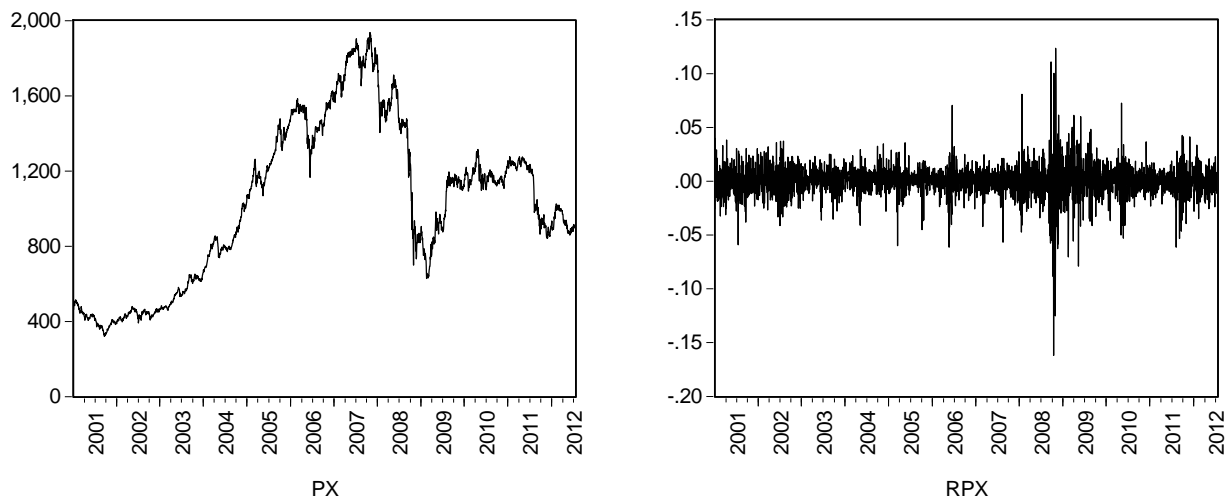

Figure 2: Czech Republic, PX daily prices and returns
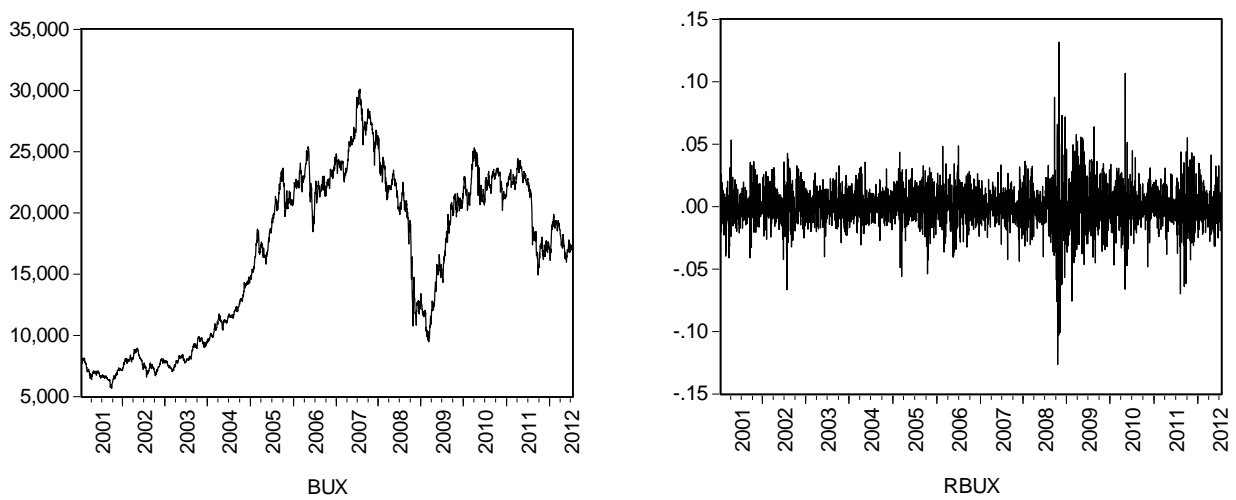

Figure 3: Hungary, BUX daily prices and returns 

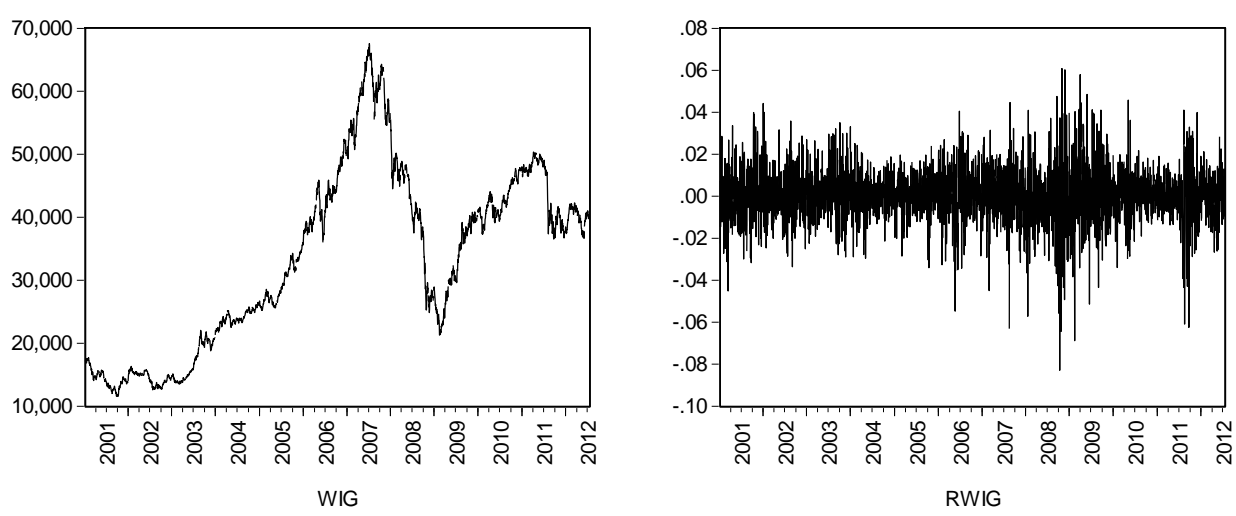

Figure 4: Poland, WIG daily prices and returns
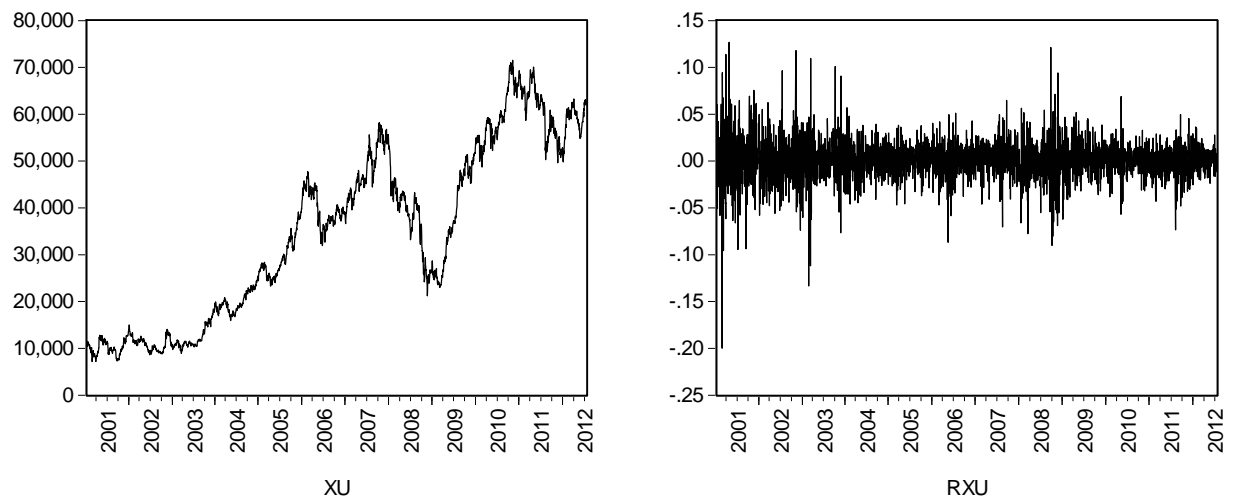

Figure 5: Turkey, XU100 (XU) daily prices and returns

Table 1 shows descriptive statistics of the return series. Most important values which are presented in the table are skewness, kurtosis and Jarque Bera statistics. Linear structural (and time series) models are unable to explain a number of important features which are leptokurtosis, volatility clustering or volatility pooling and leverage effects mostly exist in financial data. Leptokurtosis, volatility clustering or volatility pooling and leverage effects are tendency for financial asset returns. Positive skewness means that the distribution has a long right tail and negative skewness implies that the distribution has a long left tail. The kurtosis of the normal distribution is 3 . If the kurtosis exceeds 3, the distribution is peaked (leptokurtic) relative to the normal; if the kurtosis is less than 3 , the distribution is flat (platykurtic) relative to the normal. Testing normality, Jarque Bera test is used which has null hypothesis of a normal distribution and it is distributed as $\chi^{2}$ with 2 degrees of freedom.

Table 1. Descriptive Statistics 
Modeling Volatility in the Stock Markets using GARCH Models: European Emerging Economies and Turkey

\begin{tabular}{|l|c|c|c|c|c|}
\hline & RSOFIX & RPX & RBUX & RWIG & RXU \\
\hline Mean & 0.000372 & 0.000210 & 0.000274 & 0.000286 & 0.000629 \\
\hline Median & 0.000422 & 0.000721 & 0.000431 & 0.000538 & 0.001078 \\
\hline Maximum & 0.210733 & 0.123641 & 0.131777 & 0.060837 & 0.126858 \\
\hline Minimum & -0.208995 & -0.161855 & -0.126489 & -0.082888 & -0.199785 \\
\hline Std. Dev. & 0.017476 & 0.015431 & 0.016705 & 0.013419 & 0.022315 \\
\hline Skewness & -0.584360 & -0.524060 & -0.094484 & -0.298743 & -0.304936 \\
\hline Kurtosis & 31.05451 & 15.43870 & 8.833738 & 5.693070 & 9.136331 \\
\hline Jarque-Bera & 93165.14 & 18821.75 & 4102.380 & 918.8609 & 4588.531 \\
\hline Probability & 0.000000 & 0.000000 & 0.000000 & 0.000000 & 0.000000 \\
\hline Sum & 1.055895 & 0.609240 & 0.791554 & 0.829842 & 1.820462 \\
\hline Sum Sq. Dev. & 0.865858 & 0.690062 & 0.806215 & 0.521680 & 1.441544 \\
\hline Observations & 2836 & 2899 & 2890 & 2898 & 2896 \\
\hline
\end{tabular}

All series have negative skewness and high positive kurtosis. These values signify the situation that the distributions of the series have a long left tail and leptokurtic. Jarque-Bera (JB) statistics reject the null hypothesis of normal distribution at the $1 \%$ level of significance for all five variables.

In addition to investigations about the data stationarity, the level of series are also defined. Augmented Dickey-Fuller (ADF) statistics clearly reject the hypothesis of a Unit Root at the $1 \%$ level of significance for all five countries stock markets indices returns. Table 2 summarizes the ADF test results.

Table 2. ADF Test Results

\begin{tabular}{|l|c|c|c|c|}
\hline & \multicolumn{2}{|c|}{ Without Trend } & \multicolumn{2}{c|}{ With Trend } \\
\hline Variable & ADF stat & p & ADF stat & P \\
\hline RSOFIX & $-34.1348^{* * *}$ & 0.0000 & $-34.3166^{* * *}$ & 0.0000 \\
\hline RPX & $-39.7972 * * *$ & 0.0000 & $-39.8306 * * *$ & 0.0000 \\
\hline RBUX & $-26.0181 * * *$ & 0.0000 & $-26.0339 * * *$ & 0.0000 \\
\hline RWIG & $-49.1774 * * *$ & 0.0001 & $-49.1743 * * *$ & 0.0000 \\
\hline RXU & $-53.2380^{* * *}$ & 0.0001 & $-53.2319 * * *$ & 0.0000 \\
\hline
\end{tabular}

Note: $* * *$ denotes significant at the $1 \%$ level

\section{Methodology}

Volatility is an important concept for finance mostly in portfolio optimization, risk management and asset pricing. Since financial data include leptokurtosis, volatility clustering, long memory, volatility smile and leverage effects, they are insufficient 
to explain a number of important features common to much financial data by linear models. That is, because the assumption of homoscedasticity is not appropriate when using financial data (Floros 2008:35) In order to model volatility, Engle (1982) developed Autoregressive Conditional Heteroscedastic (ARCH) model which is further extended by Bollerslev (1986) to Generalized Autoregressive Conditional Heteroscedastic $(\mathrm{GARCH})$ model.

\section{ARCH Model}

$\mathrm{ARCH}$ models are based on the variance of the error term at time $t$ depends on the realized values of the squared error terms in previous time periods. The model is specified as:

$$
\begin{aligned}
& \mathrm{y}_{\mathrm{t}}=\mathrm{u}_{\mathrm{t}} \\
& \mathrm{u}_{\mathrm{t}} \sim \mathrm{N}\left(0, \sigma_{\mathrm{t}}^{2}\right) \\
& \sigma_{\mathrm{t}}^{2}=\alpha_{0}+\sum_{\mathrm{t}=1}^{\mathrm{q}} \alpha_{\mathrm{j}} \mathrm{u}_{\mathrm{t}-\mathrm{i}}^{2}
\end{aligned}
$$

This model is referred to as $\operatorname{ARCH}(q)$, where q refers to the order of the lagged squared returns included in the model. If we use $\mathrm{ARCH}(1)$ model it becomes

$$
\sigma_{t}^{2}=\alpha_{0}+\alpha_{1} u_{t-1}^{2}
$$

Since $\sigma_{t}^{2}$ is a conditional variance, its value must always be strictly positive; a negative variance at any point in time would be meaningless. To ensure that the conditional variance is strictly positive coefficient in the equation must be $\alpha_{0}>0$ and $\alpha_{1} \geq 0$. If that requirement were not satisfied, realizations of some of $\sigma_{t}^{2}$ could be negative.

\section{GARCH Model}

Bollerslev (1986) and Taylor (1986) proposed the $\mathrm{GARCH}(\mathrm{p}, \mathrm{q})$ random process. The process allows the conditional variance of variable to be dependent upon previous lags; first lag of the squared residual from the mean equation and present news about the volatility from the previous period which is as follows:

$$
\sigma_{\mathrm{t}}^{2}=\alpha_{0}+\sum_{\mathrm{i}=1}^{\mathrm{q}} \alpha_{\mathrm{i}} \mathrm{u}_{\mathrm{t}-\mathrm{i}}^{2}+\sum_{\mathrm{i}=1}^{\mathrm{p}} \beta_{\mathrm{i}} \sigma_{\mathrm{t}-\mathrm{i}}^{2}
$$

All parameters in variance equation must be positive and $\alpha+\beta$ is expected to be less than one but it is close to 1 . If the sum of the coefficients equals to 1 it is called an Integrated GARCH (IGARCH) process.

\section{GJR-GARCH}


Glosten, Jagananthan and Runkle (1993) developed the GARCH model which allows the conditional variance has a different response to past negative and positive innovations.

$$
\sigma_{\mathrm{t}}^{2}=\alpha_{0}+\sum_{\mathrm{i}=1}^{\mathrm{q}} \alpha_{\mathrm{i}} \mathrm{u}_{\mathrm{t}-\mathrm{i}}^{2}+\gamma_{\mathrm{i}} \mathrm{u}_{\mathrm{t}-1}^{2} \mathrm{~d}_{\mathrm{t}-1}+\sum_{\mathrm{i}=1}^{\mathrm{p}} \beta_{\mathrm{j}} \sigma_{\mathrm{t}-\mathrm{j}}^{2}
$$

where $d_{t-1}$ is a dummy variable that is:

$$
\mathrm{d}_{\mathrm{t}-1}= \begin{cases}1 \text { if } \mathrm{u}_{\mathrm{t}-1}<0, & \text { bad news } \\ 0 \text { if } \mathrm{u}_{\mathrm{t}-1} \geq 0, & \text { goodnews }\end{cases}
$$

In the model, effect of good news shows their impact by $\alpha$, while bad news show their impact by $\alpha+\gamma$. In addition if the coefficients $\gamma \neq 0$ and $\gamma>0$ the news impact is asymmetric and leverage effect exist respectively. The meaning of leverage effect is bad news increase volatility. In order to satisfy non-negativity condition, coefficients would be $\alpha_{0}>0, \alpha_{i}>0, \beta \geq 0$ and $\alpha_{i}+\gamma_{i} \geq 0$. Since $\gamma_{i}<0$, provided that $\alpha_{i}+\gamma_{i} \geq 0$, the model is acceptable (Brooks, 2008:405).

\section{Exponential GARCH}

Exponential GARCH (EGARCH) proposed by Nelson (1991) includes a form of leverage effects in its equation. In the EGARCH model, the specification for the conditional covariance is given by the following form:

$$
\log \left(\sigma_{\mathrm{t}}^{2}\right)=\alpha_{0}+\sum_{\mathrm{j}=1}^{\mathrm{q}} \beta_{\mathrm{j}} \log \left(\sigma_{\mathrm{t}-\mathrm{j}}^{2}\right)+\sum_{\mathrm{i}=1}^{\mathrm{p}} \alpha_{\mathrm{i}}\left|\frac{\mathrm{u}_{\mathrm{t}=\mathrm{i}}}{\sigma_{\mathrm{t}=\mathrm{i}}}\right|+\sum_{\mathrm{k}=1}^{\mathrm{r}} \gamma_{\mathrm{k}} \frac{\mathrm{u}_{\mathrm{t}-\mathrm{k}}}{\sigma_{\mathrm{t}-\mathrm{k}}}
$$

In the equation, $\gamma_{\mathrm{k}}$ represents leverage effects which accounts for the asymmetry of the model. While the basic GARCH model requires the restrictions, the EGARCH model allows unrestricted estimation of the variance (Thomas and Mitchell 2005:16). If $\gamma_{\mathrm{k}}<0$, it indicates presence of leverage effects and if $\gamma_{\mathrm{k}} \neq 0$, the impact is asymmetric. The meaning of leverage effects bad news increase volatility.

Table 3 summarizes parameters which must be statistically significant for the analysis which is mentioned above.

Table 3 : Significance Conditions of Parameters in Models

\begin{tabular}{|l|l|l|}
\hline ARCH & $\sigma_{\mathrm{t}}^{2}=\alpha_{0}+\alpha_{1} \mathrm{u}_{\mathrm{t}-1}^{2}$ & $\alpha_{1}$ \\
\hline GARCH & $\sigma_{\mathrm{t}}^{2}=\alpha_{0}+\alpha_{1} \mathrm{u}_{\mathrm{t}-1}^{2}+\beta_{1} \mathrm{~h}_{\mathrm{t}-1}$ & $\beta_{1}$ \\
\hline GJR- GARCH & $\sigma_{\mathrm{t}}^{2}=\alpha_{0}+\alpha_{1} \mathrm{u}_{\mathrm{t}-1}^{2}+\gamma_{1} \mathrm{u}_{\mathrm{t}-1}^{2} \mathrm{~d}_{\mathrm{t}-1}+\beta_{1} \mathrm{~h}_{\mathrm{t}-1}$ & $\gamma_{1}$ \\
\hline
\end{tabular}




\begin{tabular}{|l|l|l|}
\hline E- GARCH & $\log \left(\sigma_{\mathrm{t}}^{2}\right)=\alpha_{0}+\beta_{1} \log \left(\sigma_{\mathrm{t}-1}^{2}\right)+\alpha_{1}\left|\frac{\mathrm{u}_{\mathrm{t}=1}}{\sigma_{\mathrm{t}=1}}\right|+\gamma_{1} \frac{\mathrm{u}_{\mathrm{t}-1}}{\sigma_{\mathrm{t}-1}}$ & $\gamma_{1}$ \\
\hline
\end{tabular}

\section{Empirical Results}

The dependent variables are returns in all series. We have plotted the colerogram of the series and found out that that there is no ACF or PACF value out of the band. Therefore all variables are regressed on constant term. Before ARCH/GARCH model is used, we need to test whether models includes ARCH effects. This test is very important in time series analysis to assure that the model $\mathrm{ARCH}$ is appropriate for data that will be the case in the analysis. The test is one of a joint null hypothesis that all $\mathrm{q}$ lags of the squared residuals have coefficient values that are not significantly different from zero.

$$
\begin{aligned}
& \mathrm{H}_{0}: \alpha_{1}=0 \text { and } \alpha_{2}=0 \text { and } \alpha_{3}=0 \ldots \text { and } \alpha_{4}=0 \\
& \mathrm{H}_{1}: \alpha_{1} \neq 0 \text { and } \alpha_{2} \neq 0 \text { and } \alpha_{3} \neq 0 \ldots \text { and } \alpha_{4} \neq 0
\end{aligned}
$$

First step is estimating the residual $\left(\hat{\mathrm{u}}_{\mathrm{t}}\right)$ from the model then take a square of estimated residuals and regress them on q own lags to test $\mathrm{ARCH}$ of order:

$$
\widehat{\mathrm{u}}_{\mathrm{t}}^{2}=\alpha_{0}+\alpha_{1} \widehat{\mathrm{u}}_{\mathrm{t}-1}^{2}+\alpha_{2} \hat{\mathrm{u}}_{\mathrm{t}-2}^{2}+\ldots+\alpha_{\mathrm{q}} \hat{\mathrm{u}}_{\mathrm{t}-\mathrm{q}}^{2}+\mathrm{v}_{\mathrm{t}}
$$

where $v_{t}$ is an error term. From the regression, $R^{2}$ is obtained to calculate test statistics. The test statistics is defined as $\mathrm{N}$ (number of observation) $\times \mathrm{R}^{2}$.

If the value of the test statistic is greater than the critical value derived from the $\chi^{2}$ distribution, the null hypothesis is rejected. We test all models for the ARCH effect by ARCH-LM Test. Table 2 shows ARCH-LM test results.

Table 4. ARCH Test Results

\begin{tabular}{|l|c|c|}
\hline \multicolumn{1}{|c|}{ Dependent Variable of Model } & ARCH(1)LM Stat & P \\
\hline RSOFIX & $203.6634 * * *$ & 0.0000 \\
\hline RPX & $429,7907 * * *$ & 0.0000 \\
\hline RBUX & $314.0951 * * *$ & 0.0000 \\
\hline RWIG & $28.6528 * * *$ & 0.0000 \\
\hline RXU & $84.37769 * * *$ & 0.0000 \\
\hline
\end{tabular}

Note: $* * *$ denotes significant at the $5 \%$ level 
Table 4 shows that all models have ARCH effect on their residuals. Therefore, we can model residual terms by GARCH models.

Although ARCH $(\alpha)$ and $\operatorname{GARCH}(\beta)$ and coefficients are statistically significant in all four GARCH models for returns of SOFIX leverage effect and $\beta$ are not statistically significant (Table 1 in Appendix). For GARCH(1,1), GJR-GARCH(1,1), EGARCH(1,1) models, all coefficients are positive. However, $\alpha+\beta$ is not less than one that means the GARCH and GJR-GARCH models do not hold for the returns of SOFIX.

Taking in to consideration rest of the countries (Appendix: Table 2, Table 2 and Table 4 and Table 5), all coefficients are statistically significant and positive in GARCH and GJR-GARCH models but we do not need for EGARCH model this constrains. We conclude that strong GARCH and GJR-GARCH effects are apparent for returns of PX and BUX, WIG and XU and EGARCH effects the returns of five stock markets.

Interpreting the results of models, the sum of coefficient of $\alpha$ and $\beta$ less than one and volatility shocks are quite persistent. The magnitude of the coefficient $\beta$ is especially high for RWIG index among all other indices indicating a long memory in the variance. Moreover, lagged conditional variance is significantly positive and less than one indicating that the impact of old news on volatility is significant. Furthermore, the estimate of $\alpha$ is smaller than the estimate of $\beta$ in both cases that is to show negative shocks do not have a larger effect on conditional volatility than positive shocks of the same magnitude. In GJR-GARCH model $\gamma>0$, the news impact is asymmetric on the other words bad news increase volatility. In the EGARCH models, negative and significant leverage effect parameter shows the existence of the leverage effect in returns. It shows that the stock returns are negatively correlated with changes in volatility signify that volatility tends to rise following bad news and fall following good news.

\section{Conclusion}

The emerging economies are very important for growth of world economies. Stock markets are favorable indicator for economies. Although financial data such as stock markets are investigated in researches by econometric models, they have some features such as leptokurtosis, leverage effects, volatility clustering (or pooling), volatility smile and long memory which cannot be modeled by linear approaches. The study presented in this paper investigates the five emerging economies four of which are members of the European Union and the remaining one is Turkey. We have employed three GARCH type model; GARCH, GJR-GARCH and E-GARCH to specify volatility processes in returns of their stock markets namely SOFIX 
(Bulgaria), BUX (Czech Republic), PX (Hungary), WIG (Poland) and XU100 (Turkey) for 08.01.2001 -20.07.2012 period.

The results have shown that strong GARCH effects are exist all markets except Bulgarian market SOFIX, therefore it is offered to subsequent researches to investigate different ordered GARCH models for Bulgaria.

For other four markets, we have concluded that volatility shocks are quite persistent and the impact of old news on volatility is significant. Among all other markets which are examined, Polish stock market has the longest memory on variance. Additionally, the results have indicated that bad news increase volatility and leverage effect in returns exist in the markets. Future researches should examine the performance of multivariate time series models when using daily returns of international emerging markets.

\section{References}

Bekaert G, Harvey C. R. (1997) "Emerging Equity Market Volatility", Journal of Financial Economics 43: 29-77.

Bekaert G. and Harvey C. R.(1995) "Time-Varying World Market Integration". Journal of Finance 50: 403-444.

Bollerslev, T., (1986) “Generalized Autoregressive Conditional Heteroskedasticity". Journal of Econometrics, 1986, vol. 31, Issue 3, pages 307-327 .

Brooks C.,(2008) "Introductory Econometrics for Finance: Second Edition " Cambridge University Press

Dockery, E. and Vergari, F. (1997), "Testing the Random Walk Hypothesis: Evidence for the Budapest Stock Exchange." Applied Economics Letters, 4, 627-629.

Emerson, R., Hall, S. G. and Zelweska-Mitura, A. (1997) "Evolving Market Efficiency with an Application to Some Bulgarian Shares", Economics of Planning, Volume 30, 75-90

Engle, R.F. (1982) "Autoregressive Conditional Heteroskedasticity with Estimates of The Variance of UK Inflation”, Econometrica 50, 987-1008.

Filer, R.K. and Hanousek, J. (1996) "The Extent of Efficiency in Central European Equity Markets."

CERGE-EI Working Paper Series, No. 104, Prague, November

Floros C. (2008) "Modelling Volatility Using Garch Models: Evidence from Egypt and Israel" Middle Eastern Finance and Economics, (2), 31-41

Glosten, L.R., Jagannathan, R. And Runkle, D. (1993) “On The Relation Between the Expected Values and the Volatility of The Nominal Excess Return on Stocks"., Journal of Finance 48, 1779-1801.

Haroutounian M. K. and Price S. (2001) "Volatility in the Transition Markets of Central Europe", Applied Financial Economics, 11, 93-105

Hájek J. (2007), “Czech Capital Market Weak-Form Efficiency, Selected Issues”, Prague Economic Papers, 4, 303-318 
Harvey C. R. (1995) "Predictable Risk and Returns in Emerging Markets,". Review of Financial Studies, Oxford University Press For Society For Financial Studies, Vol. 8(3), 773-816.

Thomas S. and Mitchell H. (2005) "GARCH Modeling of High-Frequency Volatility in Australia's National Electricity Market”, Discussion Paper. Melbourne Centre for Financial Studies,

Mittnik S., Paolella M.S. Rachev S.T (2002) “Stationarity of Stable Power-GARCH Processes", Journal of Econometrics, 106, 97-107

Nelson, D. B. (1991) "Conditional Heteroscedasticity in Asset Returns: A New Approach" Econometrica, 59(2),

Nivet J. F. (1997) "Stock Markets in Transition: The Warsaw Experiment" Economics of Transition, Volume 5 (I), 171-183

Rockinger, M., Urga, G., (1999) "Time Varying Parameters Model to Test for Predictability and Integration in Stock Markets of Transition Economies". Cahier De Recherche Du Groupe Hec 635/1998.

Samitas, A., Kenourgios D. and Paltalidis N. (2007) "Integration and Behavioural Pattern in Emerging Stock Markets" Annual Meeting of the European Financial Management Association 2007, Vienna.

Scheicher , M., (2001). "The Comovements of Stock Markets in Hungary, Poland and The Czech Republic" International Journal of Finance And Economics Int. J. Fin. Econ. 6: 27-39

Shields K. (1997) "Stock Return Volatility on Emerging Eastern European Markets", The Manchester School Supplement: 118-138.

Svejnar J. (2002) "Transition Economies: Performance and Challenges", Journal of Economic Perspectives-Volume 16(1), Winter, 3-28

Syriopoulos, T., (2007) Dynamic Linkages Between Emerging European and Developed Stock Markets: Has The Emu Any Impact? “, International Review of Financial Analysis 16, 41-60.

Syriopoulos T. and Roumpis, E. (2009) "Dynamic Correlations and Volatility Effects in The Balkan Equity Markets" Journal of International Financial Markets, Institutions and Money, 19(4), 565-587.

Taylor, S. J. (1986), Modelling Financial Time Series, John Wiley \& Sons, Chichester.

Triandafil M. C. and Brezeanu P. (2008) "Corporate Finance Mechanisms Within East European Emerging Countries: An Analytical Approach on IT Commercial Companies", 4th International Conference of ASECU, "Development Cooperation and Competitiveness", The Bucharest Academy of Economic Studies, 22-24 May 2008, Bucharest, Romania

Worthington, A.C. and Higgs, H. (2003), "Weak-form Market Efficiency in European Emerging and Developed Stock Markets.” Queensland University of Technology Discussion Paper, No. 159, September

$\mathrm{Yu}$, J., (2002). "Forecasting Volatility in the New Zealand Stock Market", Applied Financial Economics, 2002, 12, 193-202 
Zikeš, F. (2003), "The Predictability of Asset Returns: An Empirical Analysis of Central-European Stock Markets" (Master Thesis). Charles University of Prague (IES).

\section{APPENDIX}

\begin{tabular}{|c|c|c|c|c|c|c|}
\hline \multicolumn{7}{|c|}{ Table 1: Estimated Coefficients of GARCH Models for RSOFIX } \\
\hline & \multicolumn{2}{|c|}{ GARCH(1,1) } & \multicolumn{2}{|c|}{ GJR-GARCH } & \multicolumn{2}{|c|}{ E GARCH } \\
\hline & Coefficient & $\mathrm{p}$ & Coefficient & $\mathrm{p}$ & Coefficient & $\mathrm{p}$ \\
\hline \multicolumn{7}{|c|}{ Mean Equation } \\
\hline$\alpha_{0}$ & 0.0005 & 0.0001 & 0.0004 & 0.0049 & 0.0005 & 0.0004 \\
\hline \multicolumn{7}{|c|}{ Variation Equation } \\
\hline$\alpha_{0}$ & $2.02 \times 10^{-6}$ & 0.0000 & $2.02 \times 10^{-6}$ & 0.0000 & -0.4552 & 0.0000 \\
\hline$\alpha$ & 0.1977 & 0.0000 & 0.1977 & 0.0000 & 0.3854 & 0.0000 \\
\hline$\gamma$ & - & - & 0.0043 & 0.7640 & -0.0044 & 0.5642 \\
\hline$\beta$ & 0.8320 & 0.0000 & 0.8320 & 0.0000 & 0.9785 & 0.0000 \\
\hline AIC & \multicolumn{2}{|c|}{-5.9075} & \multicolumn{2}{|c|}{-5.9068} & \multicolumn{2}{|c|}{-5.9087} \\
\hline SIC & \multicolumn{2}{|c|}{-5.8991} & \multicolumn{2}{|c|}{-5.8963} & \multicolumn{2}{|c|}{-5.8983} \\
\hline DW-stat & \multicolumn{2}{|c|}{1.9936} & \multicolumn{2}{|c|}{1.9936} & \multicolumn{2}{|c|}{1.9936} \\
\hline $\begin{array}{l}\text { ARCH- } \\
\text { LM test }\end{array}$ & \multicolumn{2}{|c|}{$8.8313 * * *$} & \multicolumn{2}{|c|}{$8.905172 * * *$} & \multicolumn{2}{|c|}{$7.786054 * * *$} \\
\hline Obs. & \multicolumn{6}{|c|}{2836} \\
\hline
\end{tabular}

Table 2: Estimated Coefficients of GARCH Models for RPX

\begin{tabular}{|c|c|c|c|c|c|c|}
\hline & \multicolumn{2}{|c|}{ GARCH $(1,1)$} & \multicolumn{2}{|c|}{ GJR-GARCH } & \multicolumn{2}{|c|}{ E GARCH } \\
\hline & Value & $\mathrm{p}$ & Value & $\mathrm{p}$ & Value & $\mathrm{p}$ \\
\hline \multicolumn{7}{|c|}{ Mean Equation } \\
\hline$\alpha_{0}$ & 0.0009 & 0.0000 & 0.0006 & 0.0023 & 0.0005 & 0.0055 \\
\hline \multicolumn{7}{|c|}{ Variation Equation } \\
\hline$\alpha_{0}$ & $4.69 \times 10^{-6}$ & 0.0000 & $6.07 \times 10^{-6}$ & 0.0000 & -0.5147 & 0.0000 \\
\hline$\alpha$ & 0.1318 & 0.0000 & 0.0727 & 0.0000 & 0.2531 & 0.0000 \\
\hline$\gamma$ & - & - & 0.1036 & 0.0000 & -0.0687 & 0.0000 \\
\hline$\beta$ & 0.8496 & 0.0000 & 0.8441 & 0.0000 & 0.9636 & 0.0000 \\
\hline AIC & -5.9192 & & -5.9291 & & -5.9282 & \\
\hline SIC & -5.9110 & & -5.9188 & & -5.9179 & \\
\hline
\end{tabular}


Modeling Volatility in the Stock Markets using GARCH Models: European Emerging Economies and Turkey

\begin{tabular}{|l|c|c|c|}
\hline DW-stat & 1.8863 & 1.8888 & 1.8890 \\
\hline \multicolumn{5}{|l|}{} \\
\hline $\begin{array}{l}\text { ARCH-LM } \\
\text { test }\end{array}$ & 0.306626 & 0.045804 & 1.096905 \\
\hline Obs. & \multicolumn{3}{|l}{} \\
\hline
\end{tabular}

\begin{tabular}{|c|c|c|c|c|c|c|}
\hline \multicolumn{7}{|c|}{ Table 3: Estimated Coefficients of GARCH Models for RBUX } \\
\hline & \multicolumn{2}{|c|}{ GARCH $(1,1)$} & \multicolumn{2}{|c|}{ GJR-GARCH } & \multicolumn{2}{|c|}{ E GARCH } \\
\hline & Value & $\mathrm{p}$ & Value & $\mathrm{p}$ & Value & $\mathrm{p}$ \\
\hline \multicolumn{7}{|c|}{ Mean Equation } \\
\hline$\alpha_{0}$ & 0.0006 & 0.0072 & 0.0003 & 0.1484 & 0.0004 & 0.0704 \\
\hline \multicolumn{7}{|c|}{ Variation Equation } \\
\hline$\alpha_{0}$ & $6.93 \times 10^{-6}$ & 0.0000 & $7.73 \times 10^{-6}$ & 0.0000 & -0.3903 & 0.0000 \\
\hline$\alpha$ & 0.0992 & 0.0000 & 0.0516 & 0.0000 & 0.1867 & 0.0000 \\
\hline$\gamma$ & & & 0.0847 & 0.0000 & -0.0561 & 0.0000 \\
\hline$\beta$ & 0.8740 & 0.0000 & 0.8751 & 0.0000 & 0.9709 & 0.0000 \\
\hline AIC & \multicolumn{2}{|l|}{-5.5976} & \multicolumn{2}{|l|}{-5.6077} & \multicolumn{2}{|l|}{-5.5990} \\
\hline SIC & \multicolumn{2}{|l|}{-5.5893} & \multicolumn{2}{|l|}{-5.5974} & \multicolumn{2}{|l|}{-5.5887} \\
\hline DW-stat & \multicolumn{2}{|l|}{1.8967} & \multicolumn{2}{|l|}{1.8978} & \multicolumn{2}{|l|}{1.8976} \\
\hline $\begin{array}{l}\text { ARCH-LM } \\
\text { test }\end{array}$ & \multicolumn{2}{|l|}{0.306626} & \multicolumn{2}{|l|}{0.045804} & \multicolumn{2}{|l|}{1.096905} \\
\hline Obs. & \multicolumn{6}{|c|}{2890} \\
\hline
\end{tabular}

\begin{tabular}{|c|c|c|c|c|c|c|}
\hline \multicolumn{7}{|c|}{ Table 4: Estimated Coefficients of GARCH Models for RWIG } \\
\hline & \multicolumn{2}{|c|}{ GARCH $(1,1)$} & \multicolumn{2}{|c|}{ GJR-GARCH } & \multicolumn{2}{|c|}{ E GARCH } \\
\hline & Value & $\mathrm{p}$ & Value & $\mathrm{p}$ & Value & $\mathrm{p}$ \\
\hline \multicolumn{7}{|c|}{ Mean Equation } \\
\hline$\alpha_{0}$ & 0.0007 & 0.0009 & 0.0005 & 0.0110 & 0.0006 & 0.0027 \\
\hline \multicolumn{7}{|c|}{ Variation Equation } \\
\hline$\alpha_{0}$ & $1.73 \times 10^{-6}$ & 0.0001 & $2.16 \times 10^{-6}$ & 0.0000 & $-\overline{2} 2486$ & 0.0000 \\
\hline$\alpha$ & 0.0652 & 0.0000 & 0.0406 & 0.0000 & 0.1361 & 0.0000 \\
\hline$\gamma$ & - & - & 0.0439 & 0.0000 & $-\overline{0} 0396$ & 0.0000 \\
\hline$\beta$ & 0.9256 & 0.0000 & 0.9244 & 0.0000 & 0.9837 & 0.0000 \\
\hline
\end{tabular}




\begin{tabular}{|l|l|l|l|}
\hline AIC & -5.9744 & -5.9799 & -5.9754 \\
\hline SIC & -5.9661 & -5.9696 & -5.9651 \\
\hline DW-stat & 1.8184 & 1.8194 & 1.8189 \\
\hline \multicolumn{3}{|l|}{} \\
\hline $\begin{array}{l}\text { ARCH-LM } \\
\text { test }\end{array}$ & 1.273223 & $3.272028^{* *}$ & 2.320454 \\
\hline Obs. & \multicolumn{3}{|c|}{2898} \\
\hline
\end{tabular}

Table 5: Estimated Coefficients of GARCH Models for RXU

\begin{tabular}{|c|c|c|c|c|c|c|}
\hline \multicolumn{7}{|c|}{ Table 5: Estimated Coefficients of GARCH Models for RXU } \\
\hline & \multicolumn{2}{|c|}{ GARCH $(1,1)$} & \multicolumn{2}{|c|}{ GJR-GARCH } & \multicolumn{2}{|c|}{ E GARCH } \\
\hline & Value & $\mathrm{p}$ & Value & $\mathrm{p}$ & Value & $\mathrm{p}$ \\
\hline \multicolumn{7}{|c|}{ Mean Equation } \\
\hline$\alpha_{0}$ & 0.0011 & 0.0005 & 0.0008 & 0.0079 & 0.0008 & 0.0023 \\
\hline \multicolumn{7}{|c|}{ Variation Equation } \\
\hline$\alpha_{0}$ & $7.55 \times 10^{-6}$ & 0.0000 & $8.33 \times 10^{-6}$ & 0.0000 & -0.3394 & 0.0000 \\
\hline$\alpha$ & 0.0982 & 0.0000 & 0.0710 & 0.0000 & 0.2078 & 0.0000 \\
\hline$\gamma$ & - & - & 0.0560 & 0.0000 & -0.0427 & 0.0000 \\
\hline$\beta$ & 0.8886 & 0.0000 & 0.8853 & 0.0000 & 0.9771 & 0.0000 \\
\hline AIC & \multicolumn{2}{|l|}{-5.0216} & \multicolumn{2}{|l|}{-5.0259} & \multicolumn{2}{|l|}{-5.0214} \\
\hline SIC & \multicolumn{2}{|l|}{-5.0133} & \multicolumn{2}{|l|}{-5.0156} & \multicolumn{2}{|l|}{-5.0111} \\
\hline DW-stat & \multicolumn{2}{|l|}{1.9744} & \multicolumn{2}{|l|}{1.9752} & \multicolumn{2}{|l|}{1.9750} \\
\hline $\begin{array}{l}\text { ARCH-LM } \\
\text { test }\end{array}$ & \multicolumn{2}{|l|}{1.830521} & \multicolumn{2}{|l|}{0.360043} & \multicolumn{2}{|l|}{1.349435} \\
\hline Obs. & \multicolumn{6}{|c|}{2896} \\
\hline
\end{tabular}

